\title{
A Dynamic Hazard-Based System of Equations of Vehicle Ownership with Endogenous Long-Term Decision Factors Incorporating Group Decision Making
}

Taha Hossein Rashidi ${ }^{1}$, Abolfazl (Kouros) Mohammadian ${ }^{2}$

Department of Civil and Materials Engineering, University of Illinois at Chicago, 842 W. Taylor St., Chicago, IL 60607, USA

${ }^{1}$ Corresponding author. Tel.: +1 312996 9840; fax: +13129962426.

E-mail addresses: thosse2@uic.edu (T.H. Rashidi), kouros@uic.edu (A. Mohammadian).

${ }^{2}$ Tel.:+1 312996 0962; fax: +1 3129962426. 


\title{
A Dynamic Hazard-Based System of Equations of Vehicle Ownership with Endogenous Long-Term Decision Factors Incorporating Group Decision Making
}

\begin{abstract}
The transportation system affects all aspects of our daily lives including relatively longterm decisions on work and home location choice and automobile ownership decisions. The interdependency existing among these three decisions jointly influences household mobility and overall travel patterns. Therefore, a dynamic modeling framework that can account for the effects of interdependencies between vehicle transaction behavior and residential and job location choices is highly desirable. These decisions are made in the household level while individuals' decisions influence the overall outcome; therefore, it is also important to incorporate a group decision making process within such modeling framework.

This study introduces a dynamic model for vehicle ownership, residential mobility, and employment relocation timing decisions. These decisions are modeled at the individual level and then sequentially aggregated to the household level if it is required. A hazard-based system of equations is formulated and applied in which work location and residential location changes are included as endogenous variables in the vehicle transaction model while other important factors such as land-use and built environment variables, household dynamics, and individuals' sociodemographics are also considered.
\end{abstract}

Keywords: Hazard Model, System of Equations, Vehicle Ownership, Transaction, Housing, Job Relocation. 


\section{Introduction}

The transportation system affects all aspects of human life including economic, social, and environmental issues. While the interaction can result in both short- and long-term effects, the impact can be more influential on decisions such as work or home location choices as well as automobile ownership decisions. One can postulate that availability of a vehicle may improve an individual's mobility and provide him or her with the opportunity to access jobs and other activities that were otherwise inaccessible. Job and home location choices, on the other hand, can influence an individual's vehicle ownership and utilization behavior. Therefore, the ransportation system cannot be accurately analyzed if the interdependencies between these influential elements are ignored.

Vehicle ownership or transaction models in the literature are used for a variety of purposes and their applications are considerably increasing (de Jong et al. 2004). Travel behavior and environmental researchers, car manufacturers, oil companies, international organizations and different levels of government employ these models to forecast oil and vehicle demand, transportation demand, energy consumption and emission levels. The recent dramatic changes in fuel price have even further stimulated the need for such models. Additionally, with increasing concerns about environmental issues and fuel consumption, a well-defined vehicle ownership model has become a vital tool for national, regional and local agencies.

Although, traditionally, vehicle ownership has been considered as an exogenous factor in the four steps of the transportation planning process (i.e. trip generation, trip distribution, mode choice and traffic assignment), it plays a significant role in almost all of these steps. For instance, availability of a private car in a household provides significantly different travel alternatives than if the household had to rely on transit and non-motorized modes alone. The availability of a 
vehicle, the number of vehicles and the type of vehicles in the household can significantly influence the household's travel decisions including destination choice, mode choice as well as route choice. Understanding the timing of the transaction is an important element for predicting the number and type of vehicles within a household fleet. Unfortunately, modeling the transaction timing is usually ignored in household vehicle ownership models. This study concentrates on presenting the results of developing a system of hazard-based equations in which predicting the timing of change is the focus of the modeling exercise.

From another perspective, one might argue that a vehicle transaction in a household is a group decision-making process. Similar to the case of purchasing other durable goods (e.g., house), all of the household members can potentially get involved in the decisions making process of automobile transaction choice. The decision to purchase or dispose of an automobile is made by household members collectively and the final transaction outcome is a product of decisions that are jointly made by all members based on their individual preferences about different alternatives.

Accordingly, a comprehensive vehicle ownership model should encompass three important and critical elements including: timing of the transactions, group decision making process, and analysis of the effects of taste variations.

Other than the vehicle transaction decision this paper studies the timing of two other major household decisions, namely, residential and job relocation decisions. Intuitively it can be understood that these household long-term decisions are inter-correlated. These interdependencies should not be ignored and this study introduces a bi-level System of Equations (SE) framework to capture them in an integrated model. At the first level household members' job and residential relocation decisions are modeled together and then these two decisions are 
sequentially used in modeling household vehicle transaction timing decisions. Other interdependencies among household decisions are ignored in the modeling framework of this study. Like the vehicle transaction timing decision, residential relocation decisions are modeled at the individual level and then aggregated to the household level through a group decision making process.

This study applies hazard-based duration models to the problem of household vehicle transaction timing decisions which is modeled in a system of equations along with household job and residential relocation timing decisions. Hazard-based models are traditionally used for modeling events timing in many fields such as economics, psychology, medical and political science (Cox 1959, Cox 1972, Cox and Oakes 1984).

The rest of the paper is organized as follows. First, a literature review is presented for vehicle ownership, job and residence location choice, and group decision making procedures. Mathematical formulations of the system of equations are presented next. The datasets used in this study are then explained and their variables are discussed. Following that, experimental results for different steps of the parameter estimation procedure are presented. Finally, conclusions and future research approaches are discussed in the final section.

\section{Literature Review}

The background section covers four major parts including a review on the previous vehicle ownership studies and their modeling structures, household job and residence location choice behavior, duration models, and group decision making analysis.

The earlier vehicle ownership models (Bates et al., 1981; Allanson, 1982; and Button et al., 1982) utilized only aggregate methods and provided aggregate estimates of the number of vehicles within the zones. These models were later improved both methodologically and also 
from a practical point of view. Vehicle ownership models can be categorized into several groups according to different characteristics of the models, as identified by de Jong et al. (2004). . These characteristics are: inclusion of car market demand and supply, aggregation level, inclusion of dynamic or static assumption for the models, car-type segmentation, inclusion of income, inclusion of competing assumption for different transaction types, inclusion of cost related variables and inclusion of other disaggregate and aggregate socio-demographic attributes..

Behavioral vehicle ownership models are usually modeled in a disaggregate form and can be categorized into two groups of static and dynamic models. Bhat and Pulugurta (1998), Whelan (2001 and 2007), and Rich and Nielsen (2001), developed static disaggregate vehicle ownership models. Although most of the early vehicle ownership models were static, a few static or (pseudo)-dynamic disaggregate vehicle ownership models have been developed since the mid 80s that applied a discrete choice approach to model household car type choices (Hensher et al., 1992). Improvements to the computational power in recent years have attracted many researchers to develop more advanced dynamic disaggregate vehicle ownership models. Dynamic carownership models assume that no transaction will take place as long as the household maintains its utility level with respect to its vehicle fleet. In other words, household taste evolution over time can justify applications of dynamic household vehicle ownership over static models (Mannering and Winston, 1985). Bunch et al. (1996) developed a dynamic car ownership model utilizing duration models for three transaction types, namely, dispose, replace and acquisition. De Jong also utilized hazard-based duration models to model vehicle type choice, annual car use, and style of driving (de Jong, 1991 and 1996; and Jong and Pommer, 1996). In general, transaction timing decision is an important dependent variable in dynamic vehicle ownership 
models and it is usually considered in such models (Mohamamdian and Rashidi, 2007 and Yamamoto et al. 1997).

The majority of disaggregate vehicle ownership models are static. These static vehicle ownership models are occasionally modeled with other household characteristics like vehicle usage (Bhat and Sen, 2006a and 2006b; and Fang, 2008). Golob and Brownstone (2005) modeled the impacts of residential density on vehicle usage and energy consumption. Cao et al. (2006) modeled neighborhood design and vehicle type choice in a static nested logit framework.

Behavioral job and residence location models have been previously studied from the economic perspective. For instance, Rouwandel (J. Rouwendal, E. Meijer (2001), J. Rouwendal, P Rietveld (1994), J. Rouwendal (1998) and J. Rouwendal (1999)) studied the household commute distance and job location search behavior in several studies. However, studying the household job and residential relocation behavior with the household decision on vehicle transaction in a joint framework is rare.

The current study proposes a non-linear system of equations using a hazard-based formulation for modeling household job and residential relocation timing decision along with household vehicle transaction time choice. The interdependency among these three household decisions is formulated in a dynamic framework using hazard duration models.

The proportional hazard model that was originally introduced by D.R. Cox in 1959 considered the failure time to be a random variable, and the survival probability is defined using the same random variable if no failure is observed. Following Cox's introduction of the hazard modeling framework, Lancaster in 1979 applied a proportional hazard model on an unemployment duration dataset. He used three different forms for the likelihood function including the product of multiplying the density function and survival function. Proportional 
hazard models have frequently been studied in econometrics and mathematics fields and many modifications have been applied to their concepts (Elbers and Ridder 1982 and Heckman and Singer 1984).

In the transportation field, Hensher and Mannering (1994) pioneered the applications of hazard-based duration models to transportation problems. Their article illustrates the basic concepts of hazard models along with the probable fields that hazard models might be applied and utilized in the area of transportation.

Bhat in 1995 also studied hazard models and applied them to transportation related problems. He studied both parametric and non-parametric hazard models for shopping activity behavior over a discrete failure time scale (Bhat 1995b). He later introduced a hazard model with the concept of utility function and utilized it in an application of activity-behavior analysis during the evening work-to-home commute (Bhat 1995a).

A small but growing number of studies in the transportation field have focused on the effects of the group decision making process on household level decisions such as vehicle ownership choice (Zhang and Fujiwara 2009). Group decision making theory has been studied mainly in the field of marketing since the 1950's. In a typical household, a husband and a wife are usually considered as the main decision makers (Qualls 1987). A measure of an individual members' influence, especially for the husband and wife, can be considered as another factor in these models (Qualls 1987). Few studies have focused on influences of husband and wife on specific vehicle choice attributes such as color, interior, accessories, size and performance features and budget considerations (e.g., price or purchasing time). Davis in 1976 reviewed the literatures related to the household decision making process and noted that a family member's 
involvement is different for different products and choices and it also varies among different families.

Another example that can discern the fact that group decision making theory has a welldeveloped history in many fields other than transportation refers to a study by McElroy and Horney in 1981. They developed an analytical framework for the household decision process utilizing the theory of demand. They worked with two-person households and defined the utility of the husband and wife, according to their consumption, level of leisure and budget using the Nash equilibrium. Unlike McElroy and Horney‘s study and many other well-developed studies on group decision making, it is a cumbersome task to find transportation related studies reflecting the group decision making mechanisms. As so, this study is not about to contribute to decision making theory, instead, the current paper presents a simple application of household decision making behavior on durable goods and long-term decisions. This study also aims to highlight and introduce the importance of group decision making in the transportation field. In order to incorporate group decision making factors in the proposed SE model, the influence of the household's husband, wife and other adults on vehicle transaction and residential timing decisions are integrated in a linear format which will be elaborated later. This linear integration of the hazard values has been commonly used or practiced in the literature because it has a simple form and it can be easily interpreted; therefore, it is employed in this study. As some examples, Qualls (1987) measured the perceived spousal influence factor by using the constant sum scale (Burns and Granbois 1977) in which a spouse is permitted to indicate his/her level of perceived influence in a particular decision, while at the same time suggesting a perception of his/her spouse's influence. Foxman et al. (1989) studied the influence perceptions of parents and one adolescent child by asking the respondents to rate their influence on the final decision of the 
household. Zhang et al. (2008) also studied the weighted influence of household members on the final decision of the household. Other than the multi-linear utility function type, they also used the household utility function with maximum and minimum types in the context of car ownership behavior.

\section{Dataset}

The Puget Sound Transportation Study (PSTS) as the first general-purpose travel panel survey in an urban area of the United States is utilized for model development in this paper (Murakami and Watterson 1992). PSTS is collected in the Seattle Metropolitan Area and its surrounding counties for ten waves from 1989 to 2002. Each wave is organized into three data files including trip information, household and individual attributes. Since residential duration which is an essential variable in the residential location timing decision model is only available in the last three waves of PSTS, only the last three waves of this longitudinal panel survey are utilized for the modeling development in this study. Other than the collected data in PSTS, land-use, built environment, and transportation network data variables for the Seattle Metropolitan Area and its surrounding counties are borrowed from the results of studies by Mohammadian and Zhang (2007) and Silva and Goulias (2007).

\section{The study Framework}

The primary objective of this study is to introduce a dynamic, and disaggregate car ownership modeling framework that can endogenously account for major life events (e.g., job or home location changes) that influence household vehicle ownership decisions. To achieve these goals, a SE framework is introduced in which the process of household decision making is studied. Group decision making theory is also utilized in all levels of the hierarchical framework as a complementary component. The modeling framework of this study that is shown in Figure 1 
consists of three major equations. In this model, job and residential relocation timing decisions are endogenously correlated to each other and they are sequentially significant in explaining the transaction time. Group decision making factors are also embedded in the general framework. Parameter estimation procedure follows the hierarchy implied in Figure 1. In other words, the residential relocation decision is initially modeled simultaneously with the job relocation timing decision for individual members of the household. Then the residential relocation individual decisions are aggregated into the household level decision through the group decision making factor estimation procedure. Consequently, the household vehicle transaction timing decision is modeled followed by the group decision making factors estimation.

[Figure 1]

\section{Methodology and Formulation}

Proportional hazard model formulation is composed of a baseline hazard part and a covariates part. Similar to other studies in the literature (e.g., Yamamoto et al. 1997), in this study the Weibull distribution is employed for the baseline hazard that captures the time variable which stands for the elapsed time since the previous failure. Yamamoto et al. (1997) examined five parametric distributions for vehicle holding duration: negative exponential, Weibull, gamma, log-logistic, and log-normal distributions, and found that the Weibull distribution provides better likelihood estimates compared to the other four distributions. Based on this finding, they applied the Weibull distribution for the baseline hazard in their succeeding vehicle holding duration studies (Yamamoto et al. 1999, Yamamoto and Kitamura 2000). The Weibull distribution has also been commonly employed in residential and employment mobility studies 
(Henley 19980 , Seko and Sumita 2007). Adopting the same distributional assumption in this study, the proportional hazard can be formulated as:

$h_{i}(t)=\lim _{\Delta t \rightarrow o} \frac{\operatorname{Pr}(t+\Delta t \geq T \geq t \mid T \geq t)}{\Delta t}=h_{i 0}(t) \times \exp \left(-\beta x_{i}\right)$

where $h_{i}(t)$ is the probability of failure for individual $i$ given that it has survived until time $T$ and the hazard probability is formulated as a function of covariates that can influence the outcome. Moreover, $h_{i 0}(t)$ is considered as the baseline hazard. Assuming a Weibull distribution for the baseline hazard in Equation 1 results in the following hazard function equation:

$h_{i}(t)=\gamma t^{\gamma-1} \exp \left(-\beta X_{i}\right)$

where $\mathrm{X}$ denotes explanatory variables, $\beta$ is the vector of parameters and $\gamma$ is the shape parameter of the Weibull distribution.

In the methodology of duration models the probability of an individual surviving until it fails at time $T$, is called the survival function and is formulated as below:

$$
S(t)=\exp \left[-\int_{0}^{t} h(u) d u\right]
$$

Finally the likelihood function which is maximized in order to estimate the baseline parameters and the covariates parameters is as shown below:

$$
L=\prod_{i=1}^{N} h_{i}(t)^{y_{i}} \times S_{i}(t)
$$

where $N$ is the number of observations and $y_{i}$ is equal to one if a failure occurs and zero otherwise.

This basic hazard formulation is further elaborated to a dynamic SE model with the endogenous variables. The parameter estimation process as it was briefly explained in Figure 1 consists of three steps. Initially, the occupation and residential relocation are endogenously 
modeled and the parameters are estimated using a two step procedure. At the first step, the endogenous variables are excluded from the SE model and a primary estimation of the model parameters are obtained using Equation [5].

$$
\left\{\begin{array}{l}
h_{O c c}^{\text {Primary }}\left(t_{O c c}, x_{O c c}\right)=\gamma t_{O c c}^{\gamma-1} e^{\beta_{O c c} x_{O c c}} \\
h_{R s}^{\text {Primary }}\left(t_{R s}, x_{R s}\right)=\gamma t_{R s}^{\gamma-1} e^{\beta_{R s} x_{R s}}
\end{array}\right.
$$

Where $t$. is the elapsed time until the residential/job relocation occurs, $h_{\text {Occ }}^{\text {Primary }}$ stands for the primary hazard of changes in occupation location and $h_{R s}^{\text {Primary }}$ stands for the primary hazard of changes in the residential location. The exogenous variables are denoted by $x . \beta_{\text {Occ }}$ is a vector for the exogenous variables of the occupation location change equation and $\beta_{R s}$ is a vector for the exogenous variables of the residential location change equation.

It is worth noting that the residential relocation model parameters in Equation [5] are estimated at the individual level and should be aggregated into the household level to reflect the household's residential relocation collective decision. To formulate this for a typical household, the utility of the husband, wife and the average utility of the children (older than 15 years of age) are included in the model. The mathematical formulation for aggregating the individual residential relocation timing decision to the household level through three influence factors in the likelihood function is shown below:

$$
L=\prod_{i=1}^{N}\left(\alpha_{\text {hus }} h_{\text {ihus }}(t)+\alpha_{\text {wife }} h_{i_{\text {wife }}}(t)+\alpha_{c h i} h_{\text {ichi }}(t)\right)^{y_{i}} \times\left(\exp \left[-\int_{0}^{t}\left[\alpha_{\text {hus }} h_{\text {ihus }}(u)+\alpha_{\text {wife }} h_{\text {iwife }}(u)+\alpha_{\text {chi }} h_{\text {ichi }}(u)\right] d u\right]\right.
$$

where $N$ is the number of households and $y_{i}$ is equal to one if the household has changed its residential location or made a transaction and is zero otherwise. $\alpha_{h u s}$ represents the husband's 
influence on the final decision of the household and similarly $\alpha_{\text {wife }}$ and $\alpha_{c h i}$ represent the wife and children's influences on the household decision. It can be noted that Equation [6] is similar to Equation [4] with the only difference being that the hazard function is composed of the weighted hazards of household members and the survival function is composed of the weighted survival values of household members while weight factors or $\alpha$ 's summation is bounded to one. In addition to the linear utility function that was utilized in this study, one can consider other functional forms similar to the ones that are used in group decision theory (Zhang et al. 2008). This task is left for future research.

It is also noteworthy that there is no obligation that only households with husband, wife and children are included in the model estimation of this study. Instead, households with different household compositions are included in the modeling estimation of this study. The household members' influence on the overall decision is proportionally justified for households with only husband and children, only wife and children, only husband and only wife.

The estimated primary job relocation model and the aggregated primary residential relocation model are then utilized in the second step of the modeling estimation using Equation [7].

$$
\left\{\begin{array}{c}
h_{O c c}\left(t_{O c c}, x_{O c c}, h_{R s}^{\text {Primary }}\right)=\gamma t_{O c c}^{\gamma-1} e^{\beta_{O c c} x_{O c c}+\beta_{O c c k s} P_{R s}^{\text {Agg Primary }}} \\
h_{R s}\left(t_{R s}, x_{R s}, h_{O c c}^{\text {Primary }}\right)=\gamma t_{R s}^{\gamma-1} e^{\beta_{R s} x_{R s}+\beta_{R s o c c} c_{O c c}^{\text {Primary }}}
\end{array}\right.
$$

Where $h_{\text {Occ }}$ stands for the hazard of changes in occupation location, $h_{R s}$ stands for the hazard of changes in residential location, $h_{R s}^{A g g \text { Primary }}$ is the linear combination of the household members' hazards based on the influence factors obtained from Equation [6], $\beta_{\text {OccRs }}$ is the coefficient of the 
endogenous variable which is obtained from the residential location change equation and $\beta_{\text {RsOcc }}$ is the coefficient of the endogenous variable which is obtained from the job location change equation.

One may argue that it is more intuitive if the endogenous residential and job relocation hazards are substituted with actual observed failure binary ( 0 for survival and 1 for failure) variables. This statement is supported by the rationale that, for example in the case of residential relocation failure, a household has a higher probability of relocating its residence if the event of job relocation takes place. Nonetheless, the hazard of job relocation may be large, but the need for a residential relocation may only manifest itself if such high hazard of job relocation results in actual job relocation. In other words, the effect of increase in job relocation is not linearly correlated with the hazards of residential relocation decision. The most important burden before alternating the hazard values with the actual dummy failure values is that hazard values have been utilized as an instrumental variable representing the endogenous variable that cannot be forecasted. Therefore, the relocation decision itself should be modeled and it cannot be directly forecasted, while in the presented formulation, the hazard values have been utilized as a representative of the actual failure values. Even if it is desired to transform the hazard values to binary values representing the failures, it is needed to define or estimate some thresholds for the tolerance level of not relocating for each household. This method of generating binary variables requires simulation methods which can input extra error to the model. Alternatively, an unobserved heterogeneity variable can be utilized in the formulation to adjust the aforementioned drawback of non-linear and non-continuous correlation between the endogenous variables when binary variables are desired. By the way, further improvement on the presented formulation was 
left as future studies and this paper does not discuss the inclusion of heterogeneity nor does it discuss alternative non-linear, and may be non-continuous, forms of endogenous covariates. Similar to the first step, individual level residential relocation hazards are aggregated to the household level and are used in the transaction model estimation. Once the results of residential and job relocation models are available, the vehicle transaction model is estimated at the individual level using Equation [8] and is later aggregated into the household level through a similar method used for residential relocation in Equation [6].

$h_{T r}\left(t_{T r}, x_{R s}, h_{R s}^{A g g}, h_{O c c}\right)=\gamma t_{T r}^{\gamma-1} e^{\beta_{T r} x_{T r}+\beta_{T r R s} h_{R s}^{A g g}+\beta_{T r O c c} h_{O c c}}$

Where $h_{T r}$ stands for the hazard of making a transaction by the household, $h_{R s}^{A g g}$ stands for the

aggregate household residential relocation effect on the transaction decision while ${ }^{h_{\text {Occ }}}$ represents the individual hazard of job relocation at a specific time. Exogenous variables are denoted by $x$, $\beta_{T r}$ is the coefficient of the exogenous variable, $\beta_{T r O c c}$ is the coefficient of the job relocation effect on the vehicle transaction and $\beta_{T r R s}$ is the coefficient of the residential relocation effect on the vehicle transaction.

Left truncating and right censoring are two of the most important aspects that should be considered while hazard-based models are developed. Right censorship is handled in this study through considering the survival function in the likelihood function. Accordingly, once the survey is terminated, the value of surviving until the end of the survey is considered in the formulation instead of the probability of the outcome failure. For treating the left censorship, few solutions are recommended, but some are presented in the paper by Guo (1993) including filtering the truncated observations or even ignoring the left censorship effects. In this study 
there is no left censorship for the residential mobility duration in PSTP, because the length of time the household has resided at the current residence was asked in the survey. The PSTP covers 13 years of data starting from 1989 ending at 2002 and there are 10 waves in this panel survey. In this study, the last three waves of the PSTP which are the waves with more useful variables are considered and the rest of the waves are utilized in order to estimate the actual values of the covariates at the failure time as well as the failure time variable. Employing this simple algorithm makes the left censoring effect to be a subtle effect which can be ignored. Therefore, residential duration has not been censored and the job duration and the vehicle ownership duration are tracked back for 10 years before the starting time of the first utilized wave. Nevertheless, the average duration of vehicle acquisition and disposal in the PSTP data is 3.5 years. Likewise, job mobility occurs, on average, every 3.2 years in the Seattle area. Therefore, tracking households for years significantly cuts down the chance of left censorship. More specifically, in the PSTP dataset only less than 10 percent of job relocations and less than 6 percent of the vehicle transactions are left censored.

\section{Independent Variables}

Many combinations of the available variables in the PSTP data are tested in this study in order to find the best set of variables. The value of the variables at any given modeling point reflects the exact value of the variable at the time the transaction behavior or occupation/residential location change is being modeled.

Spatial variables such as land-use and neighborhood accessibility variables are often ignored in vehicle ownership and transaction models. However, to the extent possible, this study has attempted to use these types of variables in model development. The results suggest that the 
population density of the Traffic Analysis Zone (TAZ) in which the household resides is a significant land-use variable. Moreover, efficiency of the transportation system measured by congestion level, road density variables, intersection density, number of workers within the TAZ area in which household resides, and many other built-environment variables are tested in this study while amongst these tested variables population density and number of workers of the home TAZ were found to be significant and were included in the model.

Additionally, changes to the household size, number of adults, children (1-5 years old) and youths (6-17 years old) are also included in the model. Furthermore, household tenure (rent/own), household income, number of vehicles in the household, and number of workers in the household were some of the household attributes that were included in the model. To account for transit friendly environment, availability of transit stops within 5 blocks of the home location was considered. This variable that represents transit availability and accessibility plays a significant role in the job location model and vehicle transaction model. The population of the home TAZ of the household and the number of workers within the home TAZ are two land-use variables which were found to be significant in the final models. Household lifestyle changes, which represent the changes in household composition, is captured in the model by a dummy variable. Duration of residence at the current location is also used in the job location change model as an explanatory variable.

In addition to household attributes, various attributes of the individual members of the households are also included in this study. Several individual specific variables are employed in the models including gender and age of the individuals at the time of failure. Work distance significantly affects the residential location models. Graduating from school was another variable included among the set of the explanatory variables. This variable captures the effects of 
transitioning from student life to working life. Employment status is also considered in this study through two dummy variables representing whether the individual has a professional or a labor job. Table 1 presents the final list of variables that are used in the models developed in this study.

[Table 1]

\section{Models and the Results}

The likelihood functions illustrated in the methodology and formulation section are coded in SAS 9.1 environment and its non-linear procedure (NLP) is applied to maximize the likelihood function. Unknown parameters are estimated using the second-derivative methods of the Trust Region Optimization (TRUREG) algorithm of NLP.

Results of the modeling practice of this study consist of three levels. The first level presents the first stage of the 2-Step estimation procedure for residential and occupation location change hazards along with the husband, wife, and children's influence estimation on the residential location change decision. The second level presents the results of the second stage of the 2-Step estimation procedure in which the residential location change hazards are aggregated into the household level and the IVs are used for parameter re-estimation in the system of Equations 5. The last level presents the vehicle transaction decision hazard model accounting for the influence of the household members on the household transaction decision.

The first stage of the job location change hazard results is presented in Table 2. Thirteen parameters are included in this model and the goodness-of-fit statistic $-2[L(C)-L(\beta)]$ is 1994.85 . This statistic follows a Chi-Squared distribution and with 12 estimated variables it is highly significant.

[Table 2] 
It should be noted that the effect of the covariates in the hazard model is facilitated by incorporating a negative sign for parameters. It can be concluded from Table 2 that the probability of a job location change decreases with age implying that older people tend to change their job location less frequently. Modeling results suggest that male workers are more likely to change their job location that females. Further, it appears that labor workers change their occupation location more frequently than others.

Households with a larger number of employed individuals tend to have a higher rate of job location changes which means people who live in households with more employed members feel more financially secure and hence can accept the risk of a job change easier.

The parameter for the Duration of Residence takes a negative sign which means the longer the household resides in a place, the less its members consider changing their jobs. According to the results presented in Table 2, if the household size increases it does not necessarily mean that household members will change their job locations. Renters are more likely to change their job locations. The reason for this might be the instability among the renters that can result in occasional change of job locations based on their residential location. Another significant and very interesting variable which is included in the model is a dummy variable representing the proximity of the transit service to the household's home. The parameter for transit availability takes a positive sign which means that the probability of changing job location decreases if transit is close enough to the household residence. Inclusion of transit accessibility variables makes the models more policy sensitive.

Similar to the job location model, the results of the parameter estimation of the residential location model of the first stage analysis are presented in Table 3. This model has a proper 
goodness-of-fit statistic $-2[L(C)-L(\beta)]$ of 1588.61 with 11 degrees of freedom which is again highly significant.

[Table 3]

Similar to the job location change hazard model the parameter for the Age variable takes a positive sign in the residential location hazard as well. This suggests that older people often do not prefer to change their locations either home or job locations. It is shown that people with professional jobs are more likely to change their residential location.

The farther people commute every day to work, the higher the probability of changing their residential location indicating individuals' preference to be closer to their job location.

Households with more employed members change their residential location less often. If the conclusion about the number of employed members is compared to the similar one in the job location hazard model of Table 2, it can be concluded that in households that have more workers, individual members are more likely to change their job location than changing their residential location. Although, a decrease in household size may increase the probability of changing residential location, any increase in the total number of children in the household can result in a higher probability hazard for residential location change.

Availability of more vehicles in the household fleet decreases the probability of changing the home location. The number of vehicles can be considered as a proxy presenting the wealth of the household. In other words, households with more vehicles typically have higher incomes and therefore they are considered to be stable and prefer to avoid the burden of changing their home location. Nonetheless, the parameter of Tenure (rent) is negative suggesting that renters may 
change their home faster than owners. This final conclusion is also well-matched with the conclusion provided for the number of vehicles variable.

It was mentioned in the previous section that both job location and residential location models are developed at the individual level. However, the residential location change decision is a group decision and should be aggregated to the household level. Therefore, the individual's influences on the final decision are estimated using Equation 6. The data input to Equation 6 consists of the estimated residential hazard function values obtained by utilizing coefficients in Table 3 as well as the dummy variable representing the household residential change decision that is equal to one if the household has moved and zero otherwise. The results of this estimation suggest that in a typical household the husband has the highest influence in the household with respect to the residential location change choice which is consistent with the findings of other researchers (Qualls 1987). A husband's influence is found to be $54.3 \%$, while the wife's influence is $32.9 \%$, and the children's combined influence contributes almost $12.7 \%$ to the final household residential change decision. As shown in Table 4, all of the t-statistics of the parameters of the group decision coefficients are statistically significant including the group decision making t-statistics suggesting that the presented influences of the household members on the household decision are meaningful.

The second stage of model development is completed by using the influence percentages and the results of parameter estimation in the first stage.

Table 4 present the results of re-estimating the job location change model. Comparing these results with the ones presented in Table 2, one can observe that as expected the sign of all parameters remains the same.

\section{[Table 4]}


Table 5 also presents the results of the second stage estimation for the residential location hazard model. Like the first stage outcomes, both models have acceptable goodness-of-fits based on the $-2[L(C)-L(\beta)]$ statistics. The difference between the estimated coefficients of the second stage and what was obtained at the previous stage is minimal.

Furthermore, group decision making factors were re-estimated following the second stage and the same results were obtained at the accuracy of two digits. Hence the same parameters were used to estimate the endogenous explanatory variables that were later used in the vehicle transaction model.

\section{[Table 5]}

The hypothesis that residential location changes and job location changes affect the household automobile ownership transaction decision is supported by the results presented in Table 6. The goodness-of-fit of the entire model is highly significant. The model has a $-2[L(C)-L$ $(\beta)$ ] statistic equal to 318.59 with 12 degrees of freedom. This statistic follows a Chi-Squared distribution and is significant at the 0.0001 levels. It is worth noting that a transaction in this study means adding at least one vehicle to the existing household vehicles or disposing of at least one vehicle from the existing household fleet.

Table 6 shows that the Probability of change in job location variable which is the actual hazard value of changing a job has a negative sign which means, if the probability of changing a job location increases, then the probability of making a vehicle transaction increases as well. Nonetheless, the Probability of change in residential location variable takes a positive sign. Therefore, one can conclude that when a household changes its residential location, it is less 
likely that their vehicle fleet will change at the same time. The reason behind this finding might be the household financial constraints and cash flow limitations due to residential re-location.

[Table 6]

The modeling results show that graduating from school and the transition from student life to post school lifestyle increases the probability of making a vehicle transaction. It appears that older people tend to reduce their vehicle transactions. Individuals who live in a household with a higher level of income are also less likely to make frequent vehicle transactions. This outcome can be rationalized by the fact that wealthier households tend to trade their vehicles with up-to-date vehicles or keep their existing vehicles and find alternative usage for them by giving them to their recently licensed relatives. Individuals who live in households with a higher number of vehicles tend to make a vehicle transaction more often while households in the neighborhoods with fewer number of workers have a larger probability of making a transaction.

To account for lifecycle changes over time, a dummy variable called change in household lifecycle is introduced to the vehicle transaction model. Household lifecycle changes can occur under many conditions, for instance, a child grows up and goes to school, a youth becomes an adult and leaves the household or gets a job, or an adult becomes a senior (65+) and retires. This dummy variable provides much information to the model and has increased the probability of making a transaction once it takes the value of one, suggesting that changes in lifecycle can trigger a vehicle transaction.

Additionally, transportation variables, transit accessibility and work distance are all included in the vehicle transaction model. People who are required to commute long distances to get to their work location have shorter ownership duration and can make a vehicle transaction 
sooner. Additionally, people who live closer to the CBD or similar areas with good transit accessibility can postpone their vehicle transaction to a later time.

Group decision making factors are also estimated at this level for vehicle transaction decisions. Like the residential re-location decision, the estimated individual decisions should be aggregated at the household level. In a typical household, again, the husband has the greatest influence on the household's final decision concerning vehicle transaction. The modeling results suggest that a husband's influence accounts for $41.0 \%$ (12.26) of household collective decision while a wife's influence is $42.5 \%$ (13.73) and the children's influence is $16.5 \%$ (5.11). It should be noted that the numbers in the parentheses are the estimated t-values of parameters. It can be observed that a husband's influence on vehicle transaction decisions is less than his influence on residential location change decisions. However, the wife and children's (15+) influence appear to be greater in the case of vehicle transaction decisions relative to the residential location change decision.

\section{Conclusion and future work}

This study introduced a dynamic integrated modeling framework in which vehicle transaction, residential relocation and employment relocation timing were modeled. A hazardbased system of equations is formulated and applied in which work location and residential relocation timings were endogenously estimated. The instrumental variables estimated from the residential and occupation relocation timing hazards were then included in the vehicle transaction model. Other important factors such as land-use and built environment variables, household dynamics, individuals' socio-demographics and group decision making factors were also considered. It was found in this study that an individual's job relocation motivates them to think more about residential relocation and vice versa. It was also found that household members 
think about making a vehicle transaction if they have already changed their job location. Nonetheless, household residential relocation prevents the household members from thinking about changing the total number of vehicles in the household.

A unique feature of the proposed modeling system was the consideration of the linear format of group decision making factors in housing and vehicle ownership choices. Therefore, the influences of the household members on these two outcomes were estimated. The group decision making factors were employed through the aggregation of household members' influences into a higher level household decision. It was found that a husband is the household member with the most influence on the household residential relocation followed by the wife. Alternatively, a wife has the highest influence in the household decision on vehicle transaction timing decisions. Although relatively small, it was found in this study that other household adults other than the husband and wife also influence the household residential and transaction timing decision.

Further improvements to the proposed modeling framework include consideration of heterogeneity in the simultaneous system of equations, development of the remaining submodules, housing search, and job location search models. Other exogenous variables including travel time related variables and more detailed land-use information should be also included in the model to make it more consistent with activity-based micro-simulation models. The interdependencies among the household members' job relocation decisions was not included in the modeling framework of this study. Effectiveness of inclusion of these interdependencies should also be examined in the future studies. 


\section{Reference}

Allanson, E. W., (1982), Car Ownership Forecasting, London: Gordon and Breach

Bates J., Roberts M., Lowe S. and Richards P., (1981), The factors affecting household car ownership, Gower Press, London

Bhat C. and Pulugurta V., (1998), A comparison of two alternative behavioral choice mechanisms for household auto ownership decisions, Transportation Research Part B: Methodological, Vol. 32, No. 1, pp. 61-75

Bhat C. R., (1995a), A Generalized Multiple Durations Proportional hazard Model with an Application to Activity Behavior During Evening work-to-Home Commute”, Transportation Research Part B, Vol. 30, No. 6, pp. 465-480

Bhat C. R., (1995b), A Hazard-Based Duration Model of Shopping Activity with NonParametric baseline Specification and Non-Parametric Control for Unobserved Heterogeneity, Transportation Research Part B, Vol. 30, No. 3, pp. 189-207

Bhat C. R., Sen, S., (2006a), The impact of demographics, built environment attributes, vehicle characteristics, and gasoline prices on household vehicle holdings and use", Working Paper, The University of Texas at Austin

Bhat C.R. and S. Sen, (2006b), Household vehicle type holdings and usage: an application of the multiple discrete-continuous extreme value (MDCEV) model, Transportation Research Part B, Vol. 40, No. 1, pp. 35-53

Bunch, D. S., Brownstone D. and Golob T. F., (1996), A dynamic forecasting system for vehicle markets with clean-fuel vehicles, World Transport Research, Vol. 1, pp. 189203

Burns A. and D. Granbois, (1977), Factors moderating the resolution of preference conflict in family automobile purchasing, Journal of Marketing Research, XIV, pp. 68-77

Button K. J., Pearman A. D. and Fowkes A. S., (1982), Car ownership modeling and forecasting, Gower Press, UK

Cao X., Mokhtarian P. L., and Handy S. L., (2006), Neighborhood design and vehicle type choice: Evidence from Northern California, Transportation Research Part D, 13 (2), pp. 133-145.

Cox D.R., Oakes D., (1984), Analysis of Survival Data, London New York Chapman and Hall

Cox, D. R., (1959), The analysis of exponentially distributed life-time with two types of failures, Journal of Royal Statistical Society, Vol. 21B, pp. 411-421

Cox, D. R., (1972), Regression models and life-tables, Journal of Royal Statistical Society, Vol. 26B, pp. 186-220

Davis H. L., (1976), Decision Making within the Household", The Journal of Consumer Research, Vol. 2, No. 4, 1976 pp. 241-260

de Jong G., Fox J., Daly A., Pietrs M. and Smit R., (2004), Comparison of Car Ownership Models, Transport Reviews, Vol. 24, No. 4, pp. 379-408 
de Jong, G. C., (1991), An indirect utility model of car ownership and car use, European Economic Review, Vol. 34, pp. 971-985

de Jong, G. C. and Pommer J. F., (1996), A competing risks model of household vehicle transactions, Paper presented at the European Transport Conference, PTRC, London, UK

de Jong, G. C., (1996), A disaggregate model system of vehicle holding duration, type choice and use, Transportation Research Part B: Methodological, Vol. 30, No. 4, pp. 263-276

Elbers C. and Ridder G., (1982), True and Spurious Duration Dependence: The Identifiability of the Proportional Hazard Model, The Review of Economic Studies, Vol. 49, No. 3, pp. 403-409

Fang, H. A., (2008), A Discrete-Continuous model of households' vehicle choice and usage, with an application to the effects of residential density, Transportation Research Part B, Vol. 42, Issue 9, pp. 736-758

Foxman E. R., P. S. Tansuhaj; K. M. Ekstrom, (1989), Family members' perceptions of adolescents' influence in family decision making, The Journal of Consumer Research, Vol. 15, No. 4., pp. 482-491

Golob T., D. Brownstone, (2005), The impact of residential density on vehicle usage and energy consumption, Working Paper, University of California, Irvine

Guo G., (1993), Event-History Analysis for Left-Truncated Data, Sociological Methodology, Vol. 23, pp. 217-243

Heckman J., B. Singer, (1984), The Identifiability of the Proportional Hazard Model, The Review of Economic Studies, Vol. 51, No. 2, pp. 231-241

Henley, A., (1998), Residential Mobility, Housing Equity and the Labor Market", Economic Journal, 108, 414-427

Hensher D. A, Barnard P. O., Smith N. C. and Milthorpe F. W., (1992), Dimensions of Automobile Demand; A Longitudinal Study of Automobile Ownership and Use, Amsterdam: North-Holland

Hensher D.A. and Mannering F. L., (1994), Hazard-Based Duration Models and Their Application to Transport Analysis, Transport Revies, Vol. 14, No. 1, pp. 63-82

Lancaster T., (1979), Econometric Methods for Duration of Unemployment, Econometrica, Vol. 47, No. 4, pp 939-956

Mannering F. and Winston C., (1985), A dynamic empirical analysis of household vehicle ownership and utilization, Rand Journal of Economics, Vol. 16, No. 2, pp. 215-236

McElroy M. B. , Horney M. J., (1981), Nash-Bargained Household Decisions: Toward a Generalization of the Theory of Demand, International Economic Review, Vol. 22, No. 2, pp. 333-349

Mohammadian A. and T. H. Rashidi, (2007) Modeling Household Vehicle Transaction Behavior: Competing Risk Duration Approach, Transportation Research Record: Journal of the Transportation Research Board, No. 2014, pp. 9-16 
Mohammadian A., Zhang Y., (2007), Investigating Transferability of National Household Travel Survey Data, Transportation Research Record, No.1993, pp. 67-79

Murakami E. and Watterson W. T., (1992), The Puget Sound transportation panel after two waves, Transportation, Vol. 19, No. 2, pp. 141-158

Qualls W. J., (1987), Household Decision Behavior: The Impact of Husbands' and Wives' Sex Role Orientation, The Journal of Consumer Research, Vol. 14, No. 2, pp. 264279

Rich, J. H. and Nielsen O. N., (2001), A microeconomic model for car ownership, residence and work location. Paper presented at the European Transport Conference 2001, PTRC, Cambridge, UK

Rouwendal J., and Meijer E., (2001), Preferences for housing, jobs, and commuting: A Mixed logit analysis. Journal of Regional Science, 41.3, pp. 475-505

Rouwendal, J. and P. Rietveld (1994b), Changes in commuting distances of Dutch households, Urban Studies, 31, pp. 1545-1557

Rouwendal J., (1999), Spatial job search and commuting distances, Regional Science and Urban Economics, 29(4), pp. 491-517

Rouwendal J., (1998), Search Theory, Spatial Labor Markets, and Commuting, Journal of Urban Economics, 43, pp. 1-22

Seko M., \& Sumita K., (2007), Effects of government policies on residential mobility in Japan: Income tax deduction system and the rental act, Journal of Housing Economics 16(2), 167-188

Silva J.A. and Goulias K.G., (2007), Using Structural Equations Modelling to unravel the influence of land use pattern on travel behaviour of urban adult workers of Puget Sound Region, Proceedings of the European Transport Conference 2007, 17-19 October, Noordwijkerhout, The Netherlands

Whelan G., (2001), Methodological advances in modeling and forecasting car ownership in Great Britain, Paper presented at the European Transport Conference 2001, PTRC, Cambridge, UK

Whelan G., (2007), Modeling car ownership in Great Britain, Transportation Research Part A, Vol. 41, pp. 205-219

Yamamoto T., Kitamura R. and Kimura S., (1999), Competing-Risks-Duration Model of Household Vehicle Transactions with Indicators of Changes in Explanatory Variables, Transportation Research Records, Vol. 1676, pp. 116-123

Yamamoto T., Kitamura R., (2000), An analysis of household vehicle durations considering intended holding durations, Transportation Research Part A, 34, pp. 339-351

Yamamoto T., Matsuda T. and Kitamura R., (1997), An Analysis of Household Vehicle Holding Durations Relative to Intended Holding Durations ( in Japanese), Infrastructure Planning Reviews, No. 14, pp. 799-808 
Zhang J. and Fujiwara A., (2009), Intra-household Interaction in Transit-Oriented Residential Choice Behavior Represented in Stated Preference Approach, Transportation Research Record, Vol. 2134, pp. 73-81

Zhang J., Kuwano, Lee B. and Fujiwara A., (2009), Modeling household discrete choice behavior incorporating heterogeneous group decision-making mechanisms", Transportation Research Part B, Vol. 43, Issue 2, pp. 230-250 
Table 1 Variables used in the models

\begin{tabular}{llll}
\hline \multicolumn{1}{c}{ Variable } & \multicolumn{1}{c}{ Definition } & Mean & Std. Dev. \\
\hline $\begin{array}{lll}\text { Individual's attributes } \\
\text { Age }\end{array}$ & Age of main driver & 45.808 & 17.143 \\
Work distance & The distance between home and work & 13.003 & 10.480 \\
Graduation & 1, if the individual has been graduated this year; 0, otherwise & 0.026 & 0.160 \\
Male & 1, if main driver is male; 0, otherwise & 0.481 & 0.500 \\
Labor & 1, if the individual has a labor job; 0, otherwise & 0.110 & 0.313 \\
Professional & 1, if the individual has a professional job; 0, otherwise & 0.299 & 0.458 \\
Attributes of the household & & \\
Number of adults & Number of household members of 18 years or older & 2.176 & 0.786 \\
Number of youths & Number of household members who are 6-17 of years old & 0.545 & 0.917 \\
Decreased HH size & 1, if the household size decreased in the last year; 0, otherwise & 0.052 & 0.222 \\
Number of children & Number of members with age between 1-5 years old & 0.158 & 0.493 \\
Income (log) & Natural LOG of the Income of the household & 11.118 & 0.604 \\
Employed & Number of household employed members & 1.509 & 0.963 \\
Fleet size & Number of vehicles held by household & 2.436 & 1.250 \\
Tenure & 1, if the household rents a home; 0 otherwise & 0.168 & 0.374 \\
Lifestyle & 1, if household lifestyle changed in the last year; 0 otherwise & 0.102 & 0.302 \\
Population & Population of the TAZ in which the household resides (X1000) & 5.082 & 1.441 \\
Workers & Number of workers of the TAZ in which the household resides (X1000) & 2.460 & 0.768 \\
Residency duration & Duration that the household has lived at the current residence & 12.118 & 11.487 \\
Transit Stop & 1, if there a transit stop at the 5 blocks of home; 0, otherwise & 0.532 & 0.499 \\
\hline
\end{tabular}


Table 2 parameter estimation for the job location change hazard model without the residential relocation endogenous variable (first stage)

\begin{tabular}{lrrr} 
Variable & Parameter & t-value \\
\hline const & 1.827 & 10.847 \\
sigma & 1.350 & 72.128 \\
Individual & & \\
\hline Age & -0.015 & & 6.855 \\
Employment Type: Laborer & -0.226 & -4.009 \\
Male & -0.735 & -16.481 \\
Household & 0.052 & 11.329 \\
\hline Number of employed members of the HHld & 0.220 & 2.802 \\
Duration of Residence & -0.261 & -2.712 \\
Increase in HHld size & 0.432 & 7.749 \\
Tenure (Rent) & 0.133 & 3.694 \\
Total number of adults & 0.092 & 1.621 \\
Total Number of 6-17 & & & \\
Transit Stop available with 5 blocks of the home & & & \\
\hline
\end{tabular}

$F(\beta)=-4267.701954$

$\mathrm{F}(\mathrm{c})=-5059.607591$ 
Table 3 parameter estimation for the residential location change hazard model without the job relocation endogenous variable (first stage)

\begin{tabular}{|c|c|c|}
\hline Variable & Parameter & $\mathrm{t}$-value \\
\hline const & -1.217 & -1.316 \\
\hline sigma & 1.049 & 13.305 \\
\hline \multicolumn{3}{|l|}{ Individual } \\
\hline Age & 0.090 & 6.031 \\
\hline Employment Type: Professional & -1.062 & -3.014 \\
\hline Work distance & -0.025 & -2.082 \\
\hline \multicolumn{3}{|l|}{ Household } \\
\hline Number employed members of the HHld & 0.608 & 3.070 \\
\hline Decrease in HHsize & -0.726 & -2.334 \\
\hline Number of kids $1-5$ & -0.438 & -2.805 \\
\hline Number of vehicles & 0.594 & 4.241 \\
\hline Population of home TAZ $(* 1000)$ & 0.342 & 3.748 \\
\hline Tenure (Rent) & -1.118 & -3.113 \\
\hline
\end{tabular}

$\mathrm{F}(\beta)=-378.2208249$

$\mathrm{F}(\mathrm{c})=-1165.325499$ 
Table 4 parameter estimation for the job location change hazard model with the residential relocation endogenous variable (second stage)

\begin{tabular}{lrrr} 
Variable & Parameter & t-value \\
\hline const & 1.226 & 4.897 \\
sigma & 1.351 & 69.669 \\
Individual & 0.007 & \\
\hline Age & -0.357 & -4.182 \\
Employment Type: Labour & -0.224 & -3.821 \\
Male & -0.519 & -9.278 \\
Household & 0.048 & 8.983 \\
\hline Number of employed members of the HHld & 0.192 & 2.385 \\
Duration of Residence & 0.331 & 3.082 \\
Increase in HHld size & -0.023 & -1.395 \\
Tenure (Rent) & 0.398 & 6.538 \\
Change in residence location * & 0.136 & 3.636 \\
Total number of adults & 0.092 & 1.549 \\
Total Number of 6-17 & & \\
Transit Stop available with 5 blocks of the home & & \\
\hline
\end{tabular}

$F(\beta)=-3696.00231$

$F(c)=-5059.607591 \quad-2[L(C)-L(\beta)]=2727.2$

* Group Decision Making Coefficients

Husband

$0 . 5 4 3 \longdiv { 5 . 0 2 }$

Wife

$0.329 \quad 2.98$

Children

$0.127 \quad 1.01$ 
Table 5 parameter estimation for the residential location change hazard model with the job relocation endogenous variable (second stage)

\begin{tabular}{|c|c|c|}
\hline Variable & Parameter & $\mathrm{t}$-value \\
\hline const & 0.219 & 0.236 \\
\hline sigma & 1.245 & 11.221 \\
\hline \multicolumn{3}{|l|}{ Individual } \\
\hline Age & 0.075 & 5.109 \\
\hline Employment Type: Professional & -1.172 & -3.285 \\
\hline Work distance & -0.024 & -1.855 \\
\hline Change in work location & -6.505 & -6.041 \\
\hline \multicolumn{3}{|l|}{ Household } \\
\hline Number employed members of the HHld & 1.119 & 4.680 \\
\hline Decrease in HHsize & -0.839 & -2.734 \\
\hline Number of kids $1-5$ & -0.353 & -2.263 \\
\hline Number of vehicles & 0.516 & 3.780 \\
\hline Population of home TAZ $(* 1000)$ & 0.335 & 3.980 \\
\hline Tenure (Rent) & -0.653 & -1.777 \\
\hline
\end{tabular}

$\mathrm{F}(\beta)=-367.81$

$F(c)=-1165.325499 \quad-2[\mathrm{~L}(\mathrm{C})-\mathrm{L}(\beta)]=1594.38$ 
Table 6 parameter estimation for the automobile ownership transaction decision hazard model

\begin{tabular}{l} 
Variable \\
\hline const \\
sigma \\
Individual \\
\hline
\end{tabular}

$\frac{\text { Parameter }}{-0.812} \frac{\mathrm{t} \text {-value }}{-0.762}$

Not being student anymore (Graduation)

$1.406 \quad 44.668$

Age

$-0.373-1.970$
0.016

Change in job location

$0.016 \quad 3.704$

Work distance

$-4.443 \quad-4.841$

$-0.004 \quad-1.001$

Household

Change in residential location

$2.326 \quad 1.145$

Income $(\log )$

$0.348 \quad 3.737$

Number of vehicles

Number of workers in home TAZ $(* 1000)$

$-0.438-11.673$

$0.108 \quad 1.837$

Transit Stop available with 5 blocks of the home

$0.171 \quad 1.940$

Change in household lifecycle

$-0.119-1.028$

$F(\beta)=-1852.603028$

$F(C)=-2011.900905 \quad-2[L(C)-L(b)]=318.5957$

Vehicle Group Decision Making Coefficients

\begin{tabular}{lrrr}
\hline Husband & 0.410 & 12.26 \\
Wife & 0.425 & 13.73 \\
Children & 0.165 & 5.11
\end{tabular}




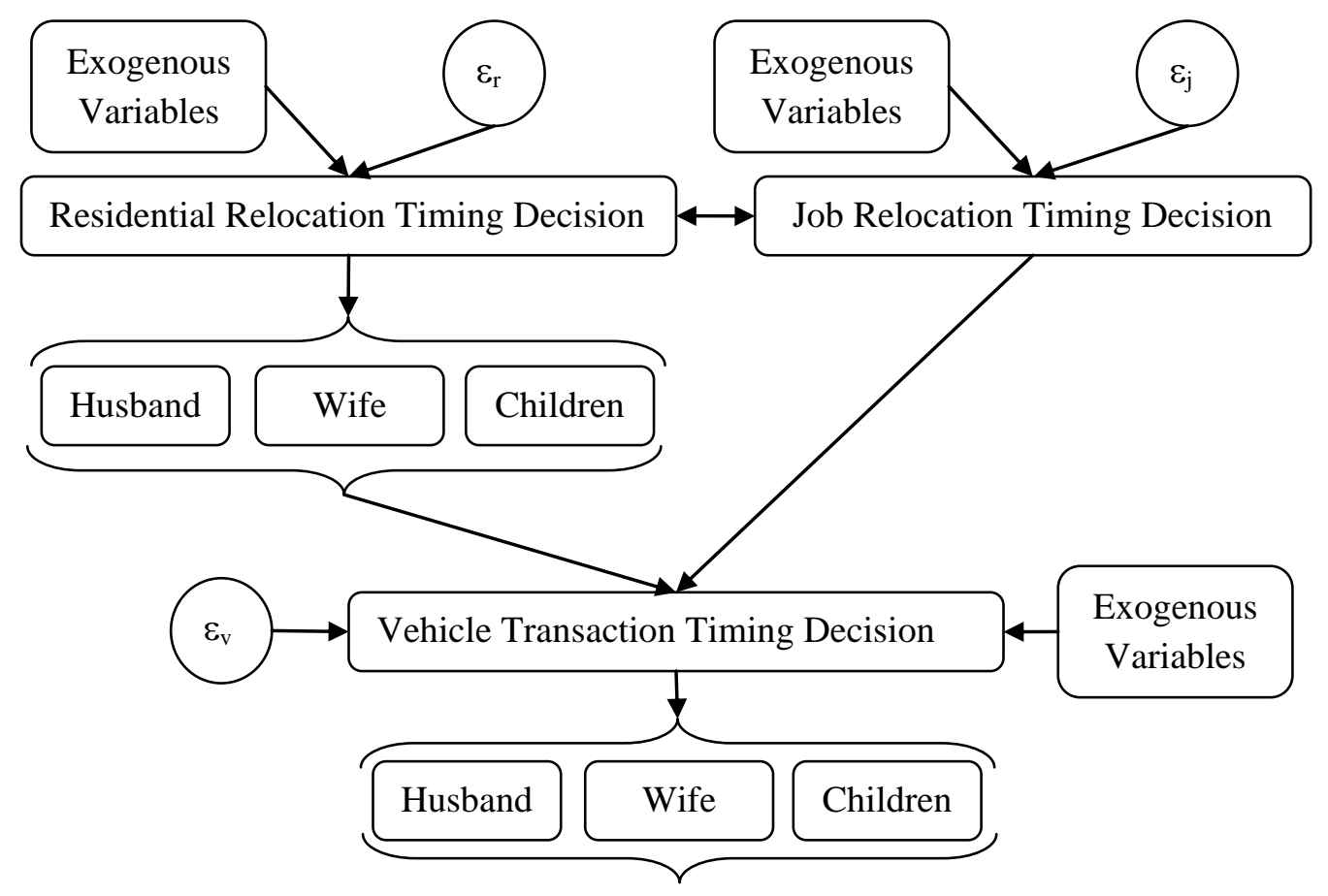

Figure 1: The proposed System of Equations (SE) modeling framework 